\title{
إشكالية التعرف على الأطفال المعاقين ذهنيا في الجزائر
}

الأستاذ الدكتور : إبراهيم بلعادي،

جامعة قالمة، الجزائر.

الملخص:

يعتبر هذا المقال بمثابة تحليل نقدي لإشكالية التعرف على الأطفال المعاقين

ذهنيا وذلك بالتساؤل حول المعايير التى تسمح بالتعرف على هولى هؤلاء الأطفال،

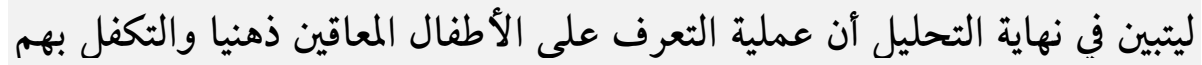

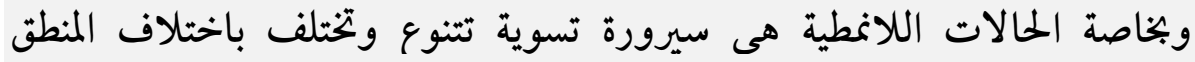
الذي يجكم ويوجه أفعال ونشاطات نختلف الفاعلين الاجتماعيين في هذا المجال.

\section{Résumé :}

Cet article représente une analyse critique de la problématique de l'identification des enfants handicapés mentaux en s'interrogeant sur les normes qui permettent d'identifier ces enfants. En fin d'analyse il apparait que l'identification et la prise en charge des enfants handicapés mentaux (notamment les cas atypiques) est un processus de normalisation qui obéit à différentes logiques qui orientent les actions des différents acteurs sociaux dans ce domaine. 


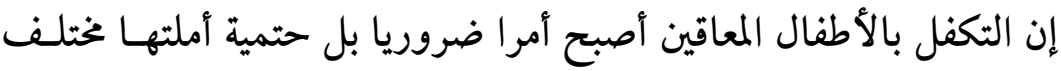

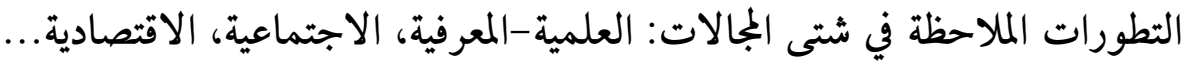

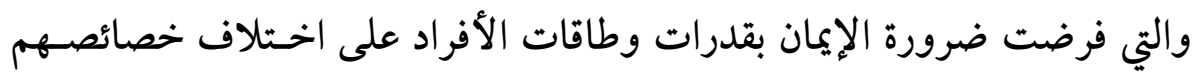

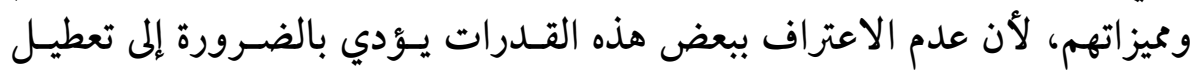

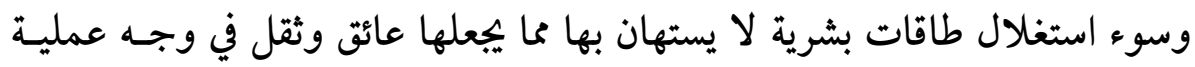
التنمية الشاملة ناهيك عن تأثيرها السلبي على التـوازن والانسـام بـام الكلـي داخـل

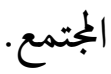

ويرتبط التكفل"la prise en charge" بهؤلاء الأطفال المعاقين ذهنيا

بإشكالية التعرف "La problématique de l'identification" عليهم وبخاصة الإنة

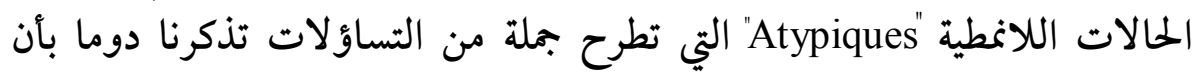

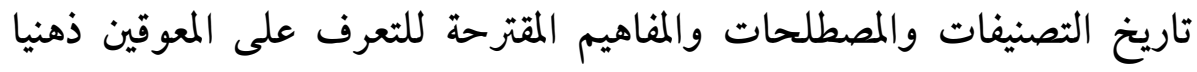

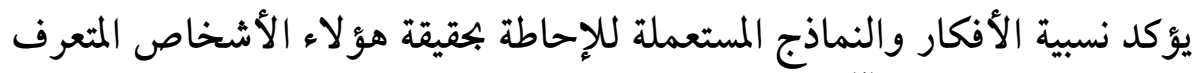

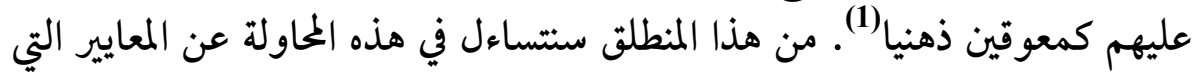

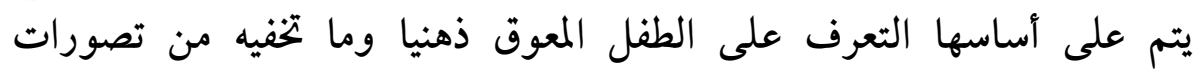

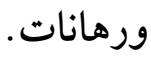

\section{أولا: منظومة التكفل بالأطفال المعاقين والأصناف الخاصة:}

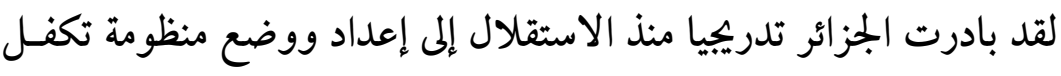

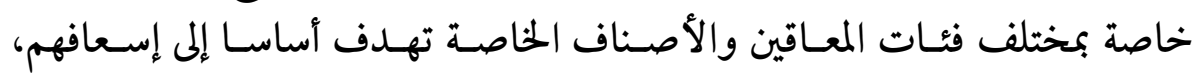

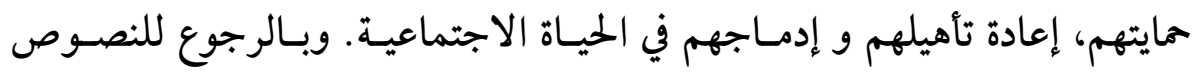

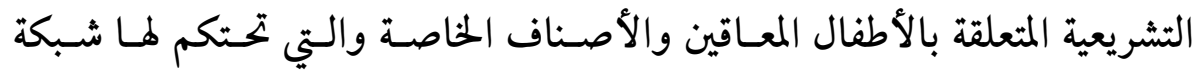

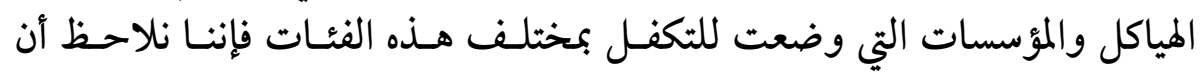
منظومة النكفل هذه بنيت أساسا على ثلاث قطاعات: قطاع الإسعاف و المساعدة. 


$$
\text { > }
$$

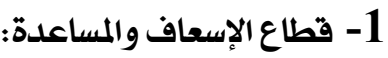

ويهتم بالطفولة، المرأة، الأسرة والمسنين.

بخصوص الطفولة فإنه يضم مؤسسات الطفولة المسعفة والمكلفة "باستقبال الأطفال المسعفين من الولادة إلى سن ثمانية عشر (18) والتكفل بهم ليلا ونهارا

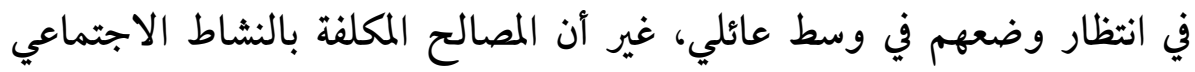

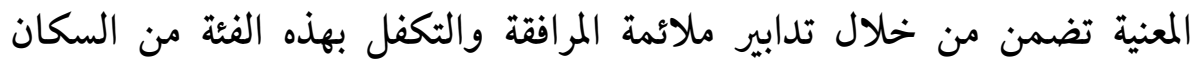

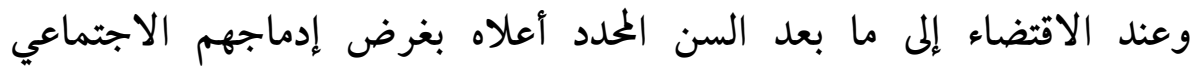
والمهني '(2) كما يضم أيضا دور استقبال اليتامى ضحايا الإرهاب والمكلفة "باستقبال

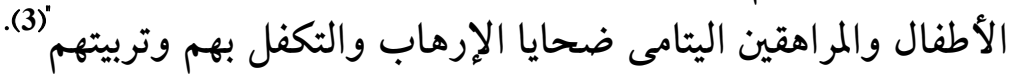
بخصوص المرأة فنجد المراكز الوطنية التي تضمن "استقبال الفتيات والنساء

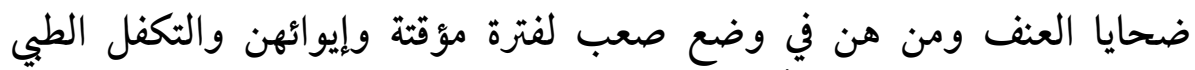

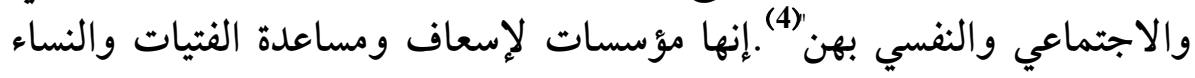

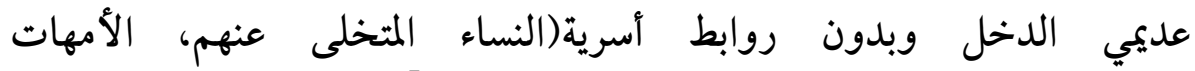

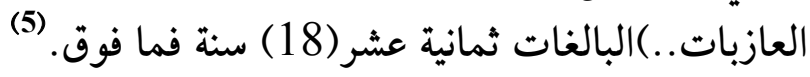

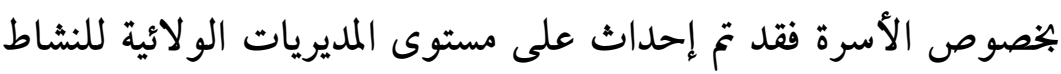

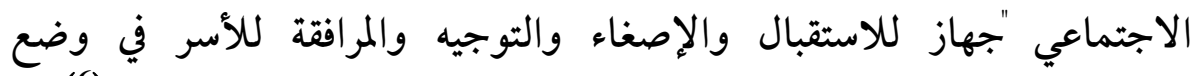

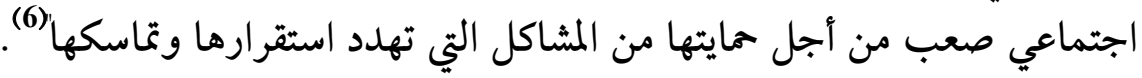

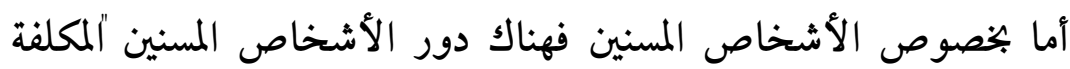
باستقبال الأشخاص المسنين البالغون من العمر 65 سنة فما فوق ولاسيما منهم: • الأشخاص المسنون المحرومون و / أو بدون روابط أسرية. 
• الأشخاص المسنون في وضعية اجتماعية صعبة و/أو بدون روابط

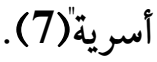

أخيرا وفي نفس القطاع أي قطاع الإسعاف والمساعدة نجد مؤسسات ديار الرحمة

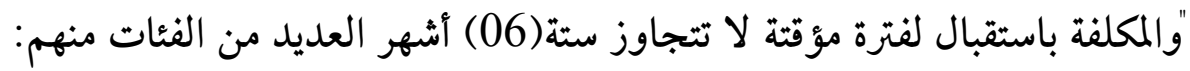
• • الأشخاص المسنين عديمي الدخل و / أو بدون روابط عائلية. • • الأشخاص المحرومين المصابين بأمراض مزمنة.

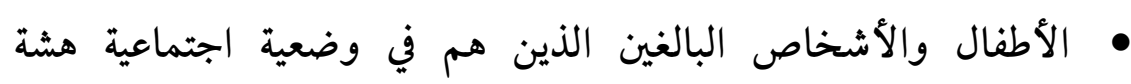
و/ أوالذين يواجهون صعوبات نفسية.

كل شخص يحتاج لمساعدة محددة مبررة قانونا (8). 2- 2 قطاع الحمايـة:

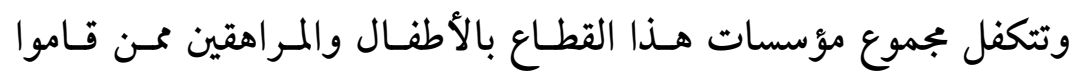

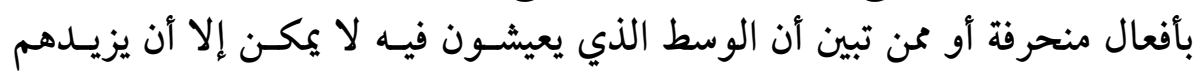

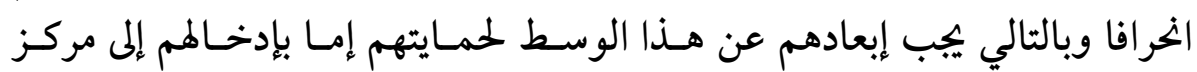

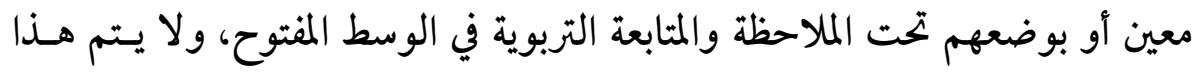

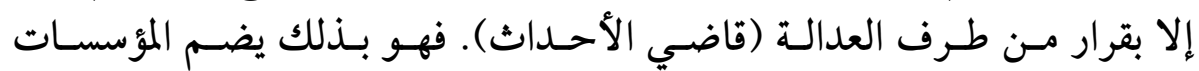

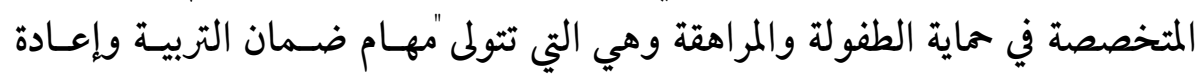

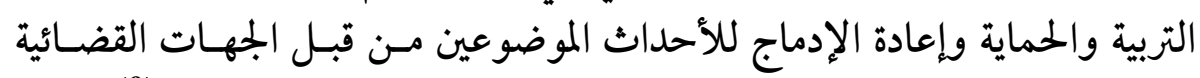

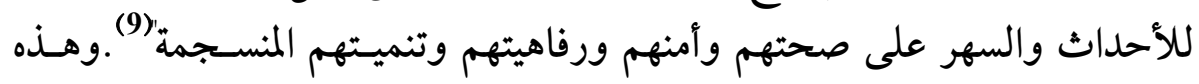
المؤسسات هي أربعة أصناف:

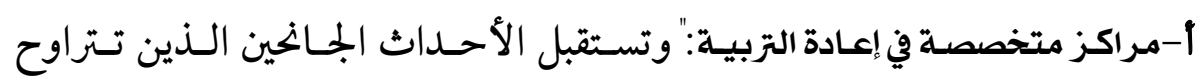

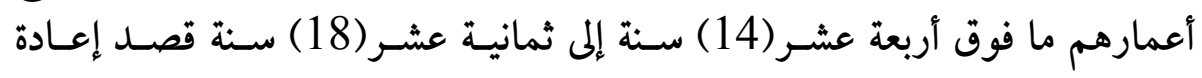
تربيتهم. 


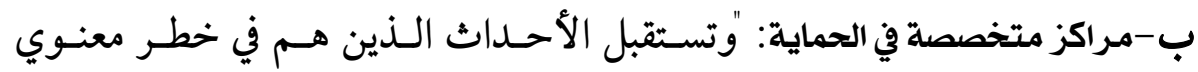

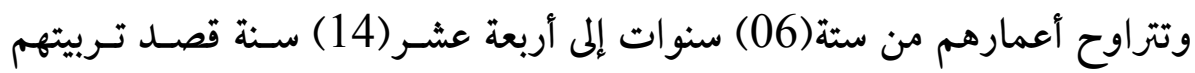

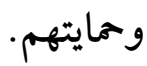

ج -المراكز المتعددة الخدمات لوقايـة الشبيبة: و وتستقبل الأحسداث الجـانحين و / أو في

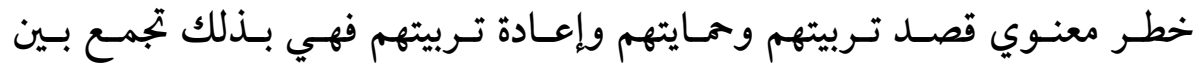
المؤسستين المذكورتين أعلاه في فضاء واحد.

د-مصالح الملاحظة والتربية في الوسط المفتوح: "وتسهر على متابعة الأحداث في خطرئ معنوي وفي حرية محروسة بأمر من قاضي الأحداث' (10).

3- قطاع الإعاقة:

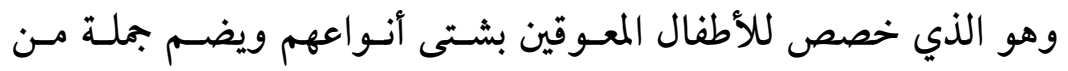

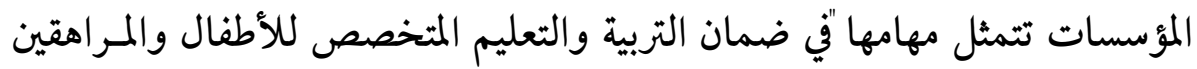

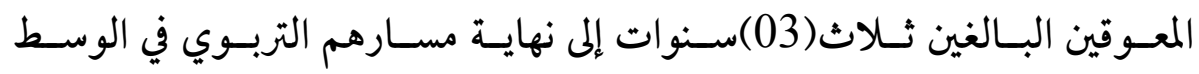

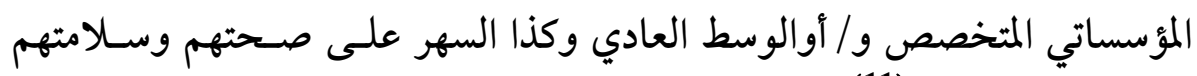
ورفاهيتهم وتنميتهم' (11).وهذه المؤسسات هي كالآلتي:

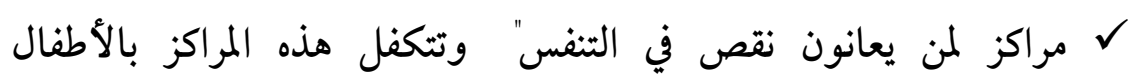
والمراهقين الذين يعانون من نقص في التنفس (12).

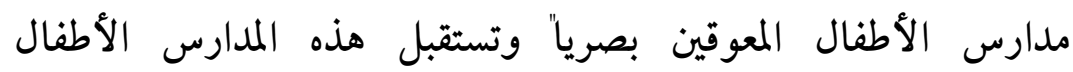

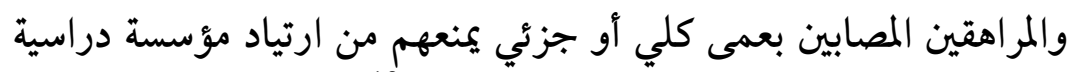

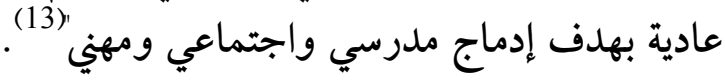
ح مدارس الأطفال المعوقين سمعيا "وتستقبل هذه مدئ المدارس الأطفال

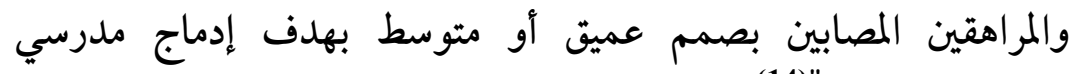
واجتماعي ومهني "(14). 
المراكز النفسية البيداغوجية للأطفال المعوقين حركيا وتستقبل هـذه المراكـز

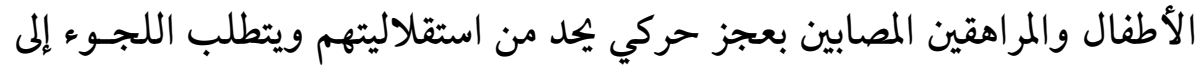

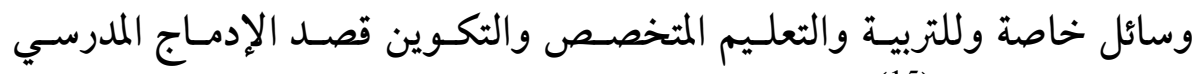
الاجتماعي والمهني' (15).

المراكز النفسية البيداغوجية للأطفال المعوقين ذهنيا "وتستقبل هـذه المراكـز

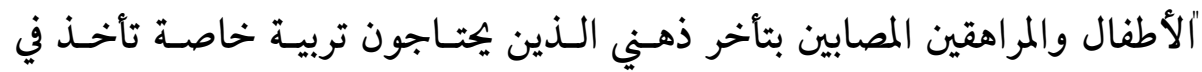
الحسبان الجوانب النفسية'(16).

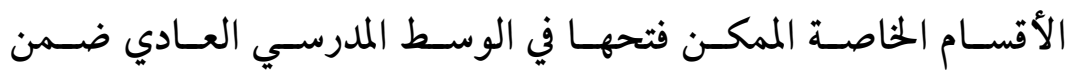

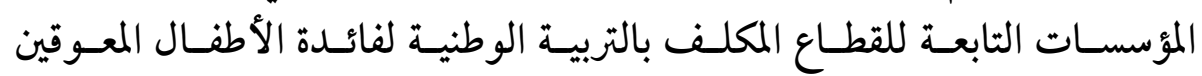

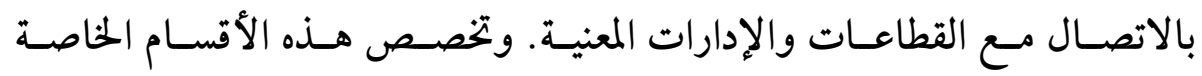

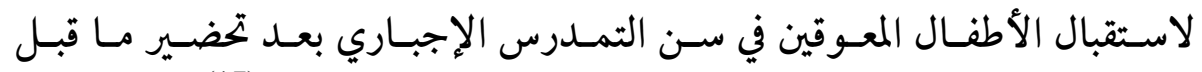

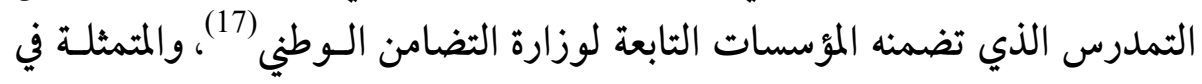

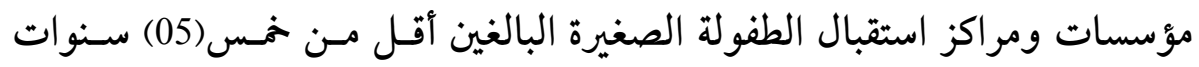

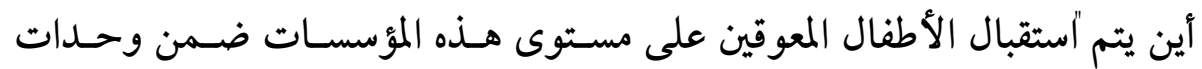
مهيئة خصيصا لهم أو يدجون في مجموعات الأطفال السليمين" (18). ويمكن توزيع المؤسسات والمصالح التي وضعت للتكفل بهؤلاء الأصسناف حسب كل قطاع كالآتي: 


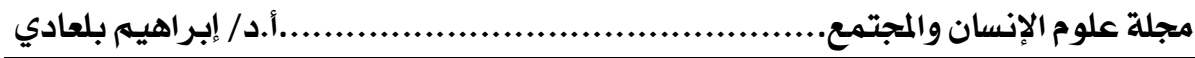

جدول يوضح توزيع مؤسسات التكفل حسب القطاعات

\begin{tabular}{|c|c|}
\hline القمطـاع & المـؤسعســـة \\
\hline \multirow{6}{*}{ الإسعاف والمسـاعدة } & مؤسسات الطفولة المسعفة \\
\hline & دور استقبال اليتامى ضحايا الإرهاب \\
\hline & ضائراكز الوطنية لاستقبال الفتيات والنساء ومن هن في وضع صعب \\
\hline & دور الأشخاص المسنين \\
\hline & ديار الرحمة \\
\hline & والمرافقة للأسر في وضعبال والإصغاء والتوجيه \\
\hline \multirow{6}{*}{ الحمــايلة } & مراكز متخصصة في إعادة التربية \\
\hline & مر اكز متخصصة في الحماية \\
\hline & مراكز متعددة الخدمات لوقاية الشبيبة \\
\hline & المفتوح \\
\hline & مراكز لمن يعانون نقص في التنفس \\
\hline & مدارس الأطفال المعوقين بصريا \\
\hline
\end{tabular}




\begin{tabular}{|c|c|}
\hline \multirow{5}{*}{ الإعــاقة } & مدارس الأطفال المعوقين سمعيا \\
\hline & حركيا لمراكز النفسية البيداغوجية للأطفال المعوقين \\
\hline & ذهنيا \\
\hline & ضمن مؤسسات ومرات المهآة خصيصا للأطفال العاقين استقبال الطفولة \\
\hline & 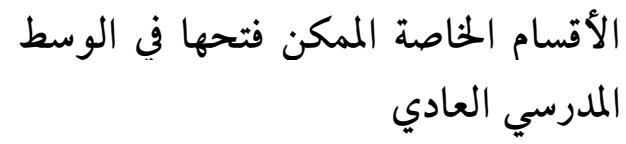 \\
\hline
\end{tabular}

ثانيا: إشكالية التعرف على الأطفال المعاقين ذهنيا انطلاقا من هذا التصنيف ومن طبيعة مؤسسات ومصالح كل قطاع نستطيع ملاحظة الآتي: 1 - قطاع الإسعاف والمساعدة :

وله الأسر التي تعيش أوضاعا اجتماعية صعبة تجعلها في حاجة للتوجيه والمرافقة والارشاد الأسري لمساعدتها على تجاوز المشاكل التي تهدد استقرارها

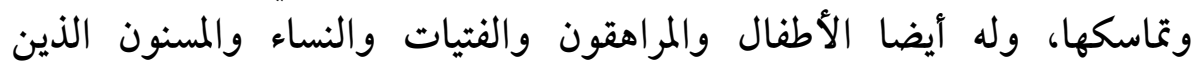
يشتركون أساسا في خاصية واحدة هي في الواقع عدم قدرتهم على تأمين معيشتهم

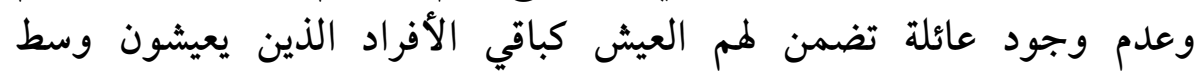
عائلاتهم. بعبارة أخرى إنهم المشردون اجتماعيا أي أولئك الذين بهكم أسئم أسباب 


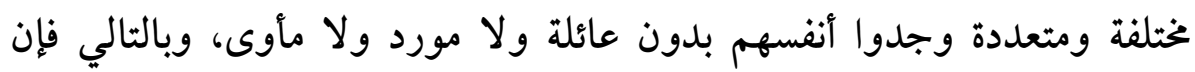

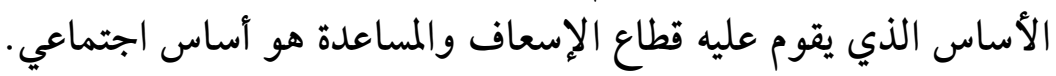

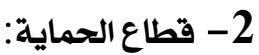

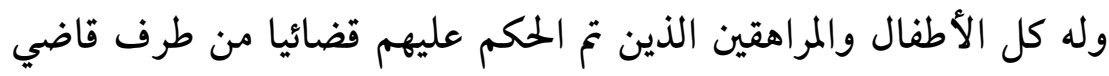

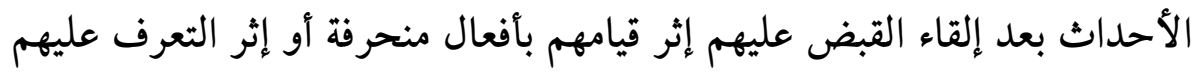

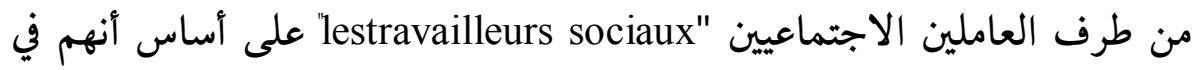

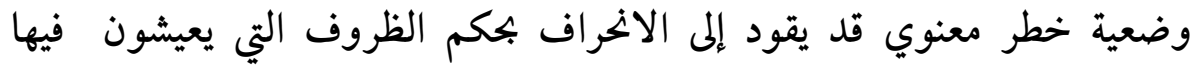

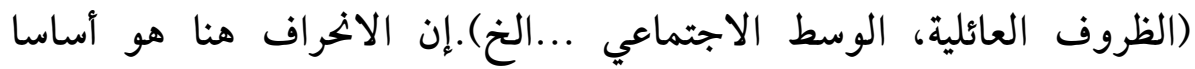

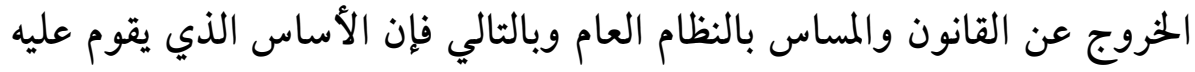
قطاع الحماية هو أساس قضائي.

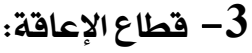

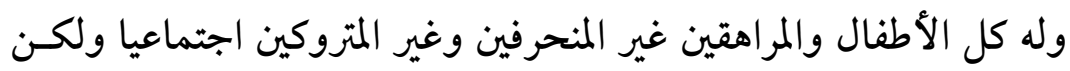

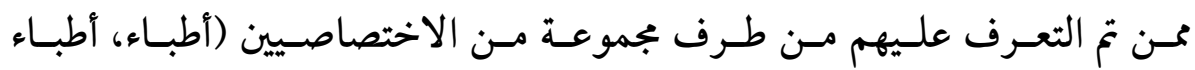

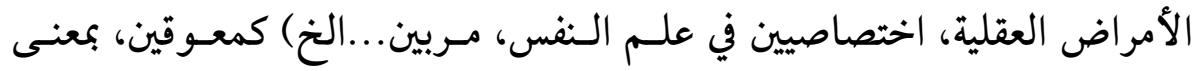

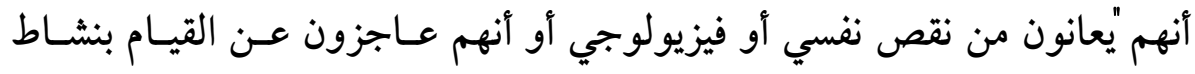

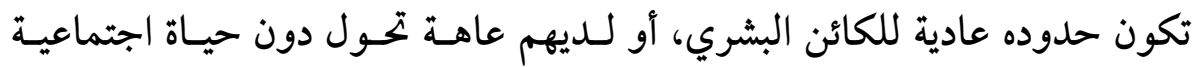
عادية أو تمنعها" (19).

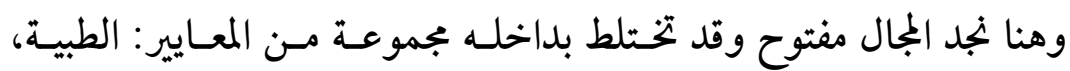

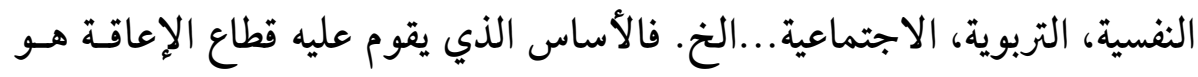

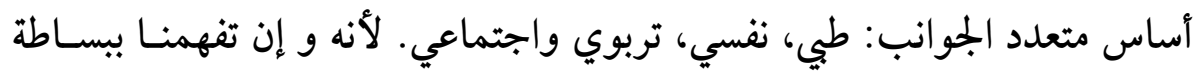

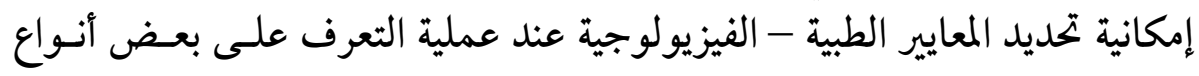

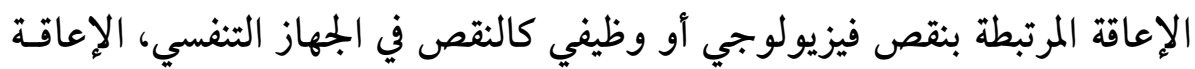

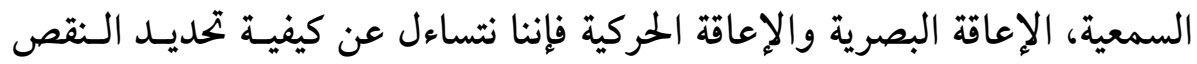
النفسي وحدود النشاط العادي للكائن البشري ومعنى الحياة الاجتماعية العادية. 
انطلاقا من هذه الملاحظة يتضح تماما بأن سيرورة التعرف على مختلف

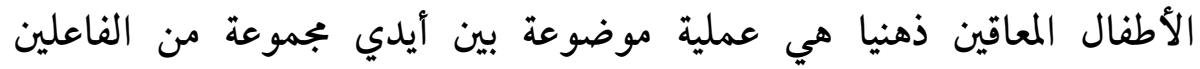

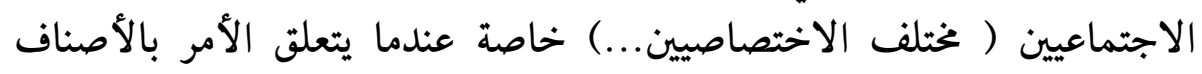

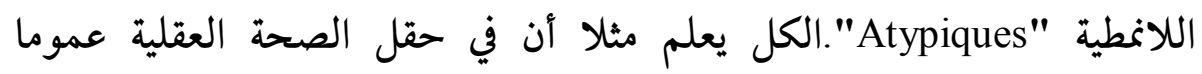

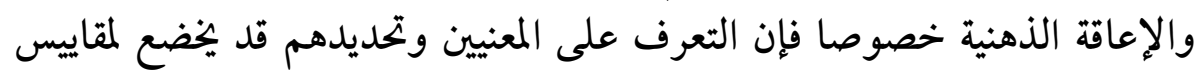

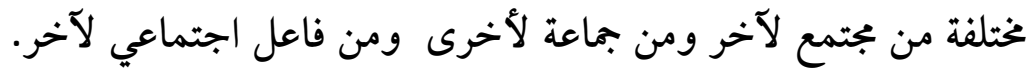

إذ تتوقف هذه المقاييس على التقاليد السائدة والأطر المرجعية والمنطلقات

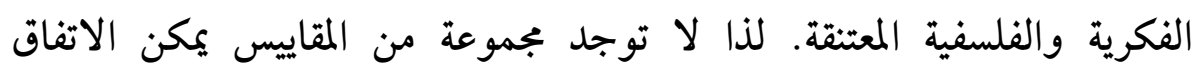
عليها(20)، بل قد تكون خاضعة لأحكام قيمية آنية أو حتى إيديولوجية أكثر منه

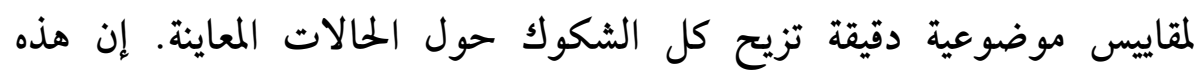

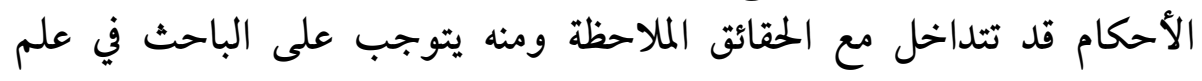
الاجتماع التساؤل حول هذه الظواهر حتى لو قدمت له تحت غطن غطاء خطاب

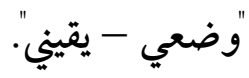

إن الإعاقة الذهنية وبخاصة الحالات اللانمطية تبقى بالنسبة لنا إنتاجات

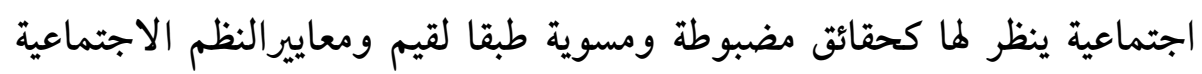

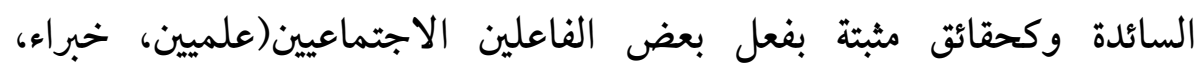

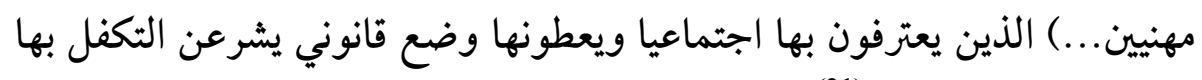
إداريا، ماليا ومؤسساتيان)

إن الاكتفاء بتناول الإعاقة الذهنية، كحقيقة موضوعية قائمة بذاتها

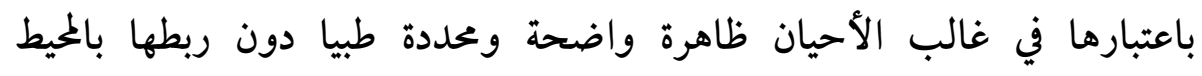

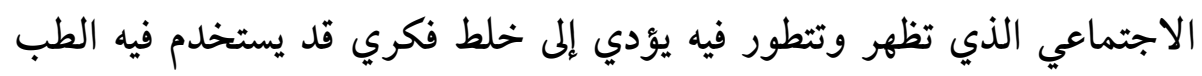
وخاصة الطب العقلي لأغراض اجتماعية وقد يصب فئ في النهاية في مصب فئ "لاتجاه

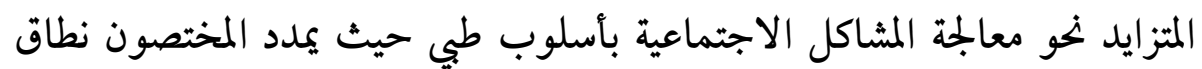
تخصصهم ليشمل مجالات لديهم معرفة أو قدرة ضئيلة بصددهالئ (22). 
إنها المعالجة الطبية المتزايدة للمشكلات الاجتماعية أو ما يمكن تسميته

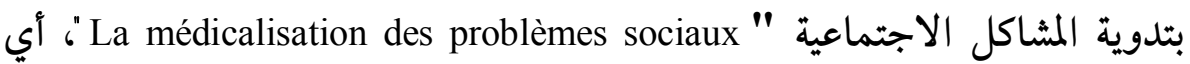

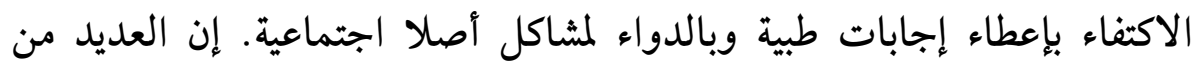

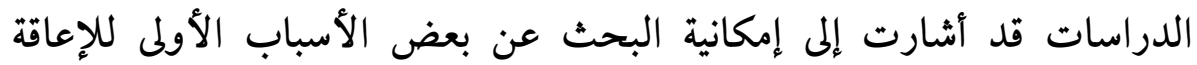

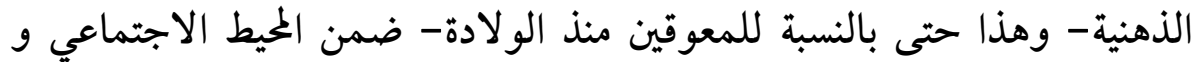
ظروفه: ظروف الحمل، ظروف الولادة، التغذية في السنوات الأولى...(23). إن الخلط بين الإعاقة والمرض يعتبر انزلاق خطير جدا لأنه يبرر- بحجة تئة

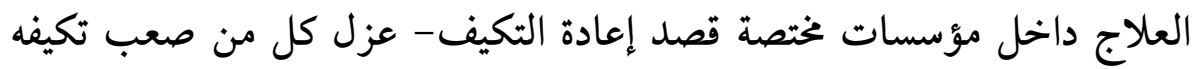

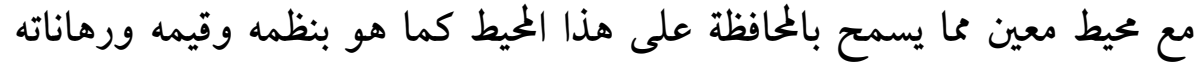

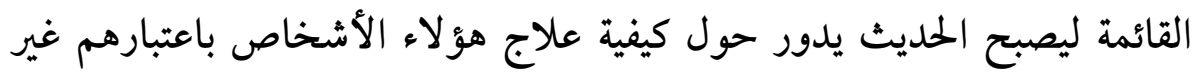

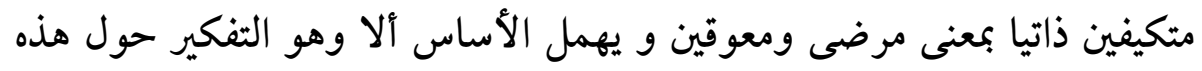

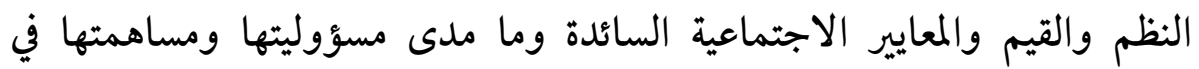

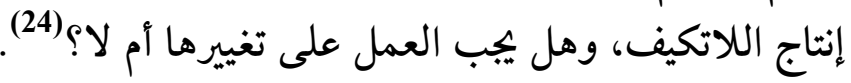

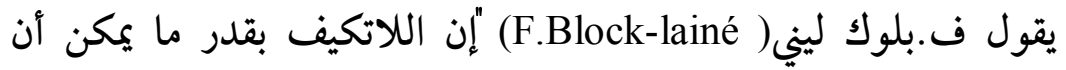

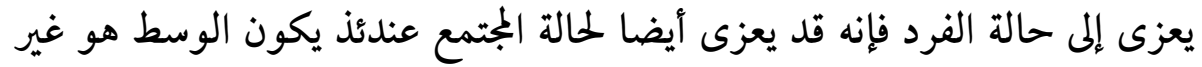

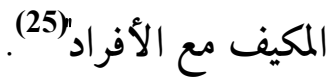

إن التساؤل حول كيفية التعرف على مختلف أصناف الأطفال المعاقين

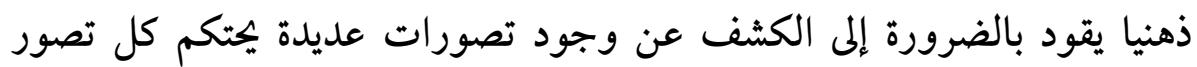

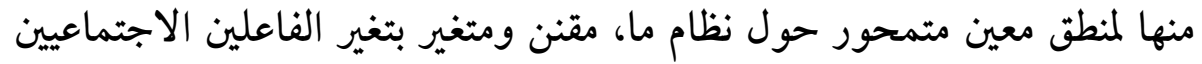

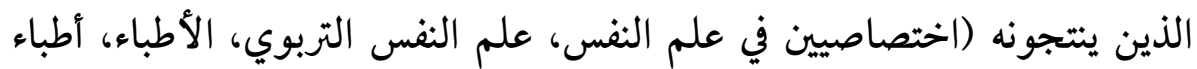

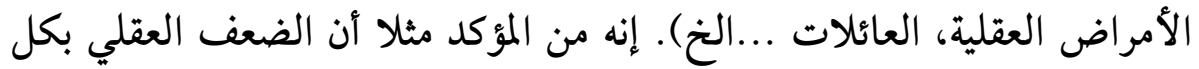

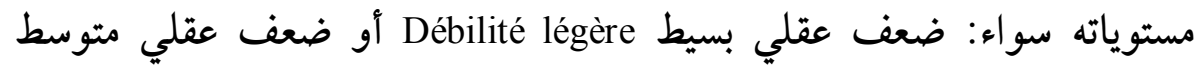
نébilité profonde أو ضعأ Débilité moyenne

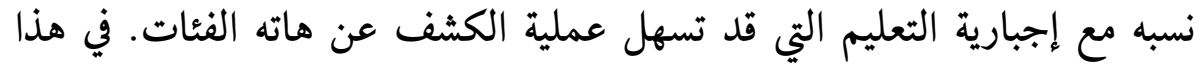

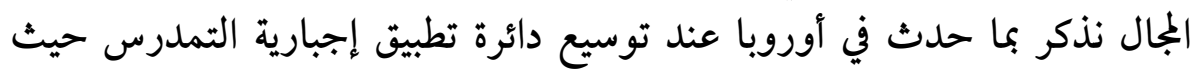


عرفت ظاهرة الضعف العقلي ارتفاعا عدديا هائلا ومعه تزايد في عدد أقسام

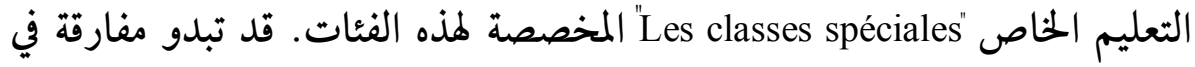
كون توسيع دائرة التعليم وتعميمه وإجباريته يؤدي إلى ارتفاع عدد المصنفين كمعوقين ذهنيا.

لكن هذه المفارقة يجب فهمها في علاقة مع المعايير الاجتماعية-الثقافية

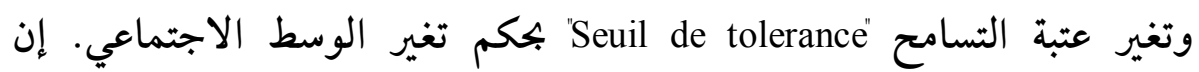
الأطفال من ينعتون بالضعف العقلي البسيط أو المتوسط وكذلك من لهم بعض العض

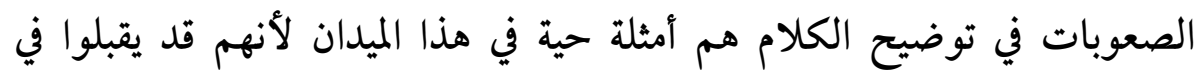

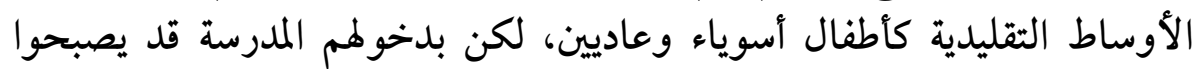

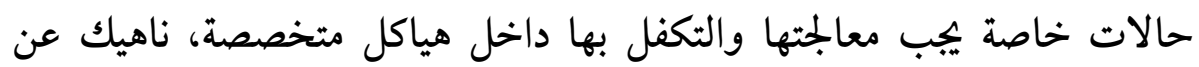
المعايي المعتمدة للتعرف عليهم والتي تختلف من بجتمع لآخر وفت التقاليد السائدة في ذلك المجتمع والفلسفة التي يعتنقها ومدى تقبله لهذه الظاهرة وطبيعة المياكل

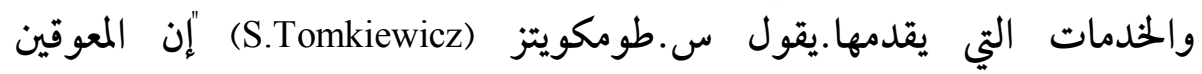

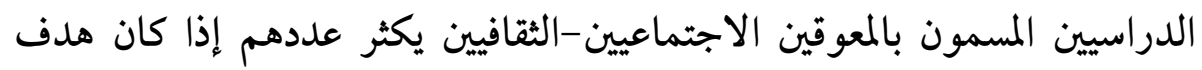
المدرسة الابتدائية في تلك البلد هو تكوين عباقرة ويقل عددهم إذإن كانت أولوية

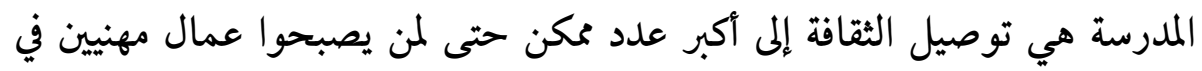

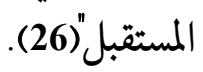

مثال آخر نستدل به عن تعدد المعايير التي تسمح بالتعرف على الطفل

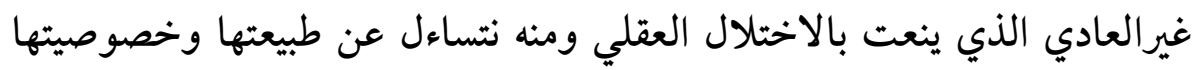

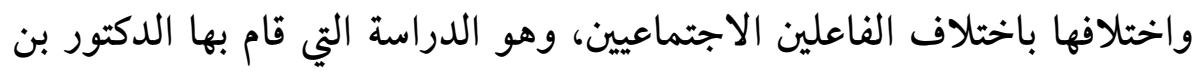

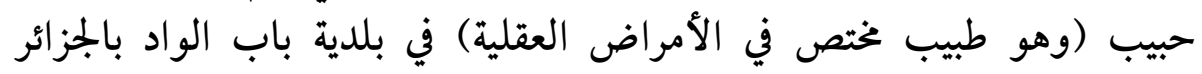

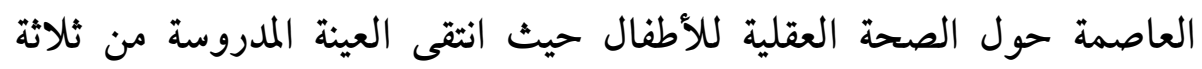

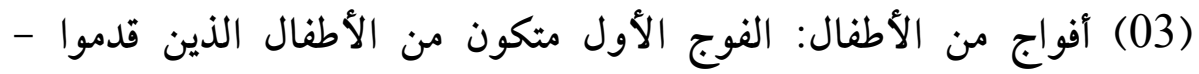

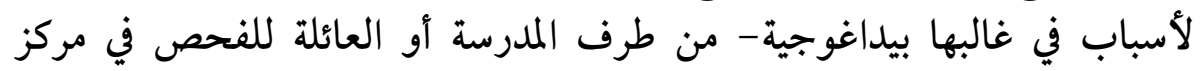

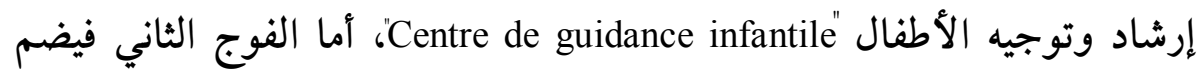




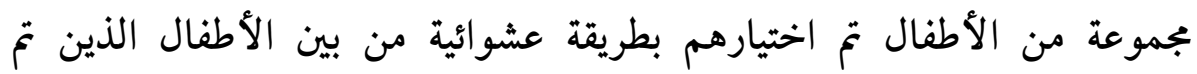

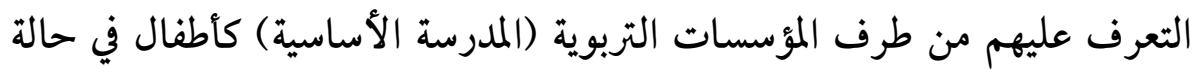

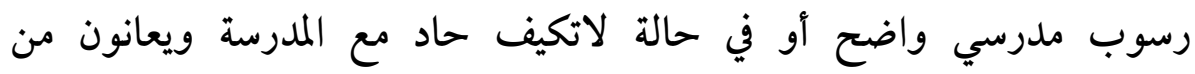

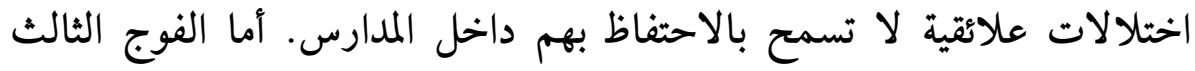

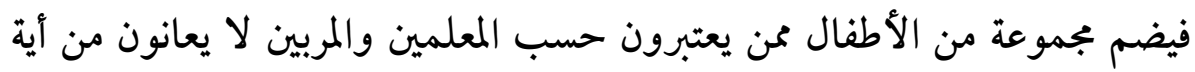

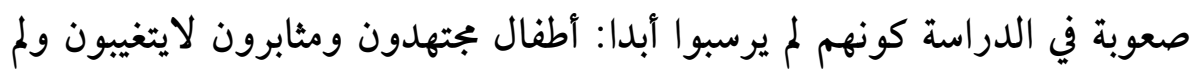

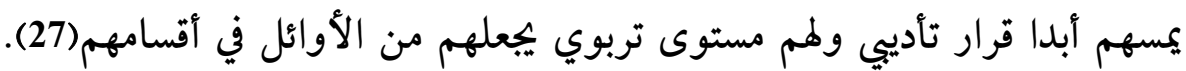

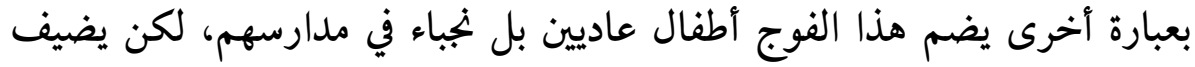

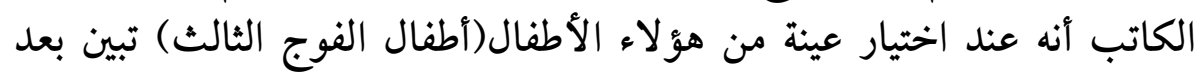

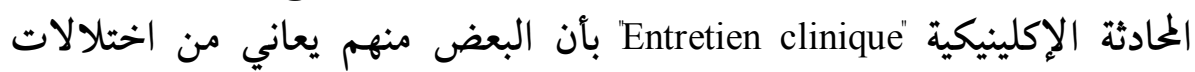

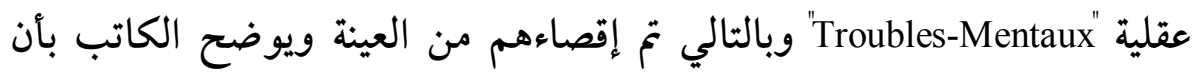
هذه الاختلالات لم تشد انتباه لا المدرسة ولا العائلة.

يتضح من خلال هذا المثال التباين الواضح بين المعايير المدرسية-الثقافية والعائلية والمعايير الطبية و دورها في التعرف على الاختلالالات العقلية.

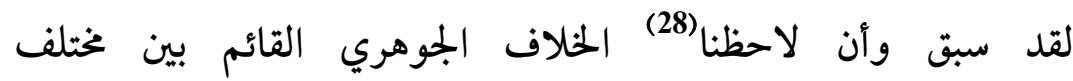

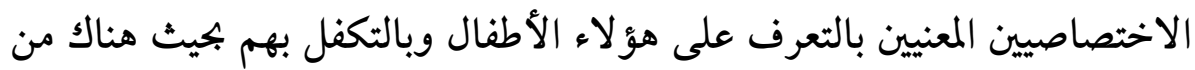

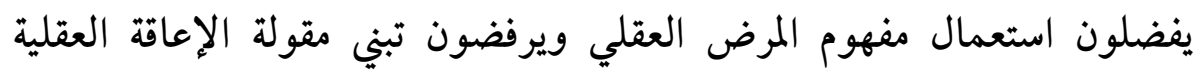

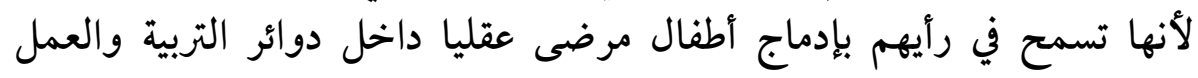

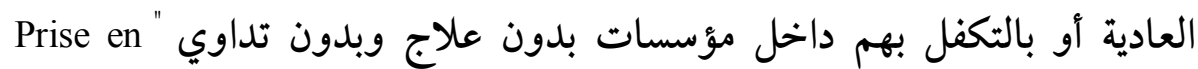
"charge démédicalisée

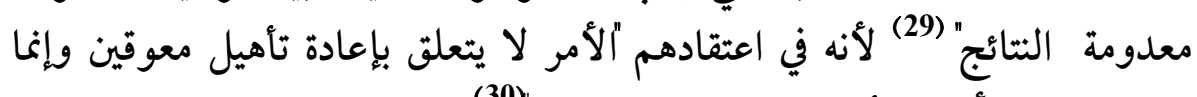
بتقديم علاج لأطفال أذكياء لكن مرضى عقليا'(30).

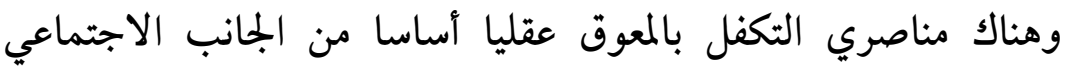

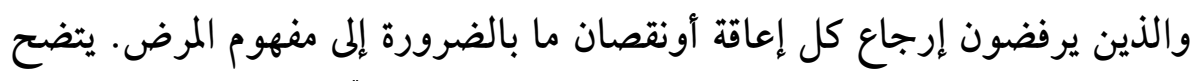

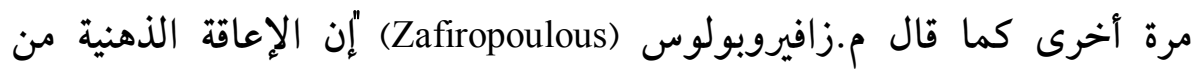


الناحية المعرفية هي موضوع غامض ورهان سلطة بالنسبة لمختلف الاختصاصيين

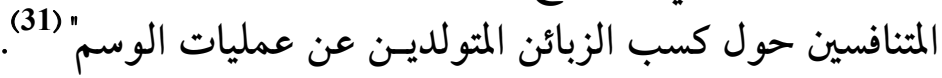

لقد تبين لنا ميدانيا في أبحاث سابقة (32) أن هناك العديد من حالات الأطفال الذين وقع خلاف بشأنهم بين مختلف الاختصاصيين العاملين بالمراكز

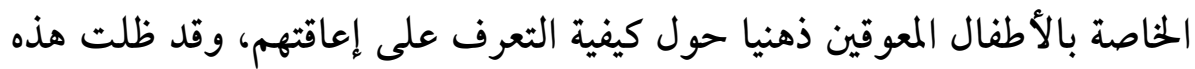

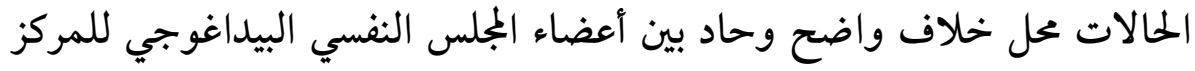

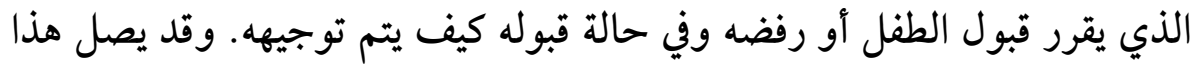
الخلاف إلى حد حسم المسألة عن طريق التصويت لإرضاء الجميع.

لقد ذهبت بعض الدراسات إلى حد الكشف عما يمكن تسميته بهيمنة

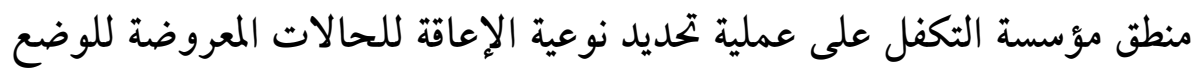

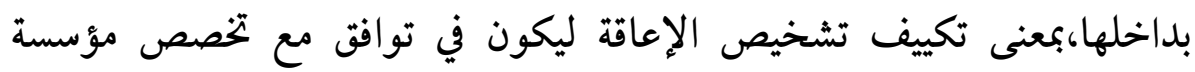

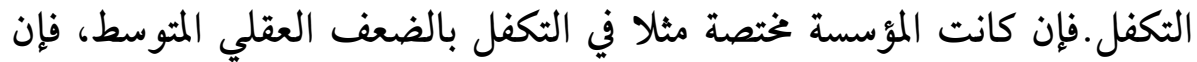

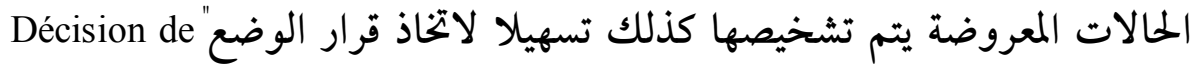
placement

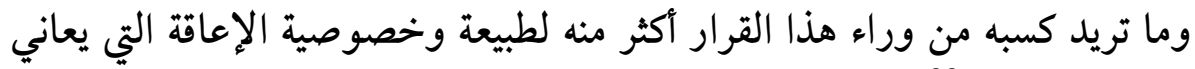
منها هذا الطفل (33).

لقد أكد الأستاذ ج.ك.قويو) J.C.Guyot أن ما يلفت الانتباه عند تحليل ملفات الوضع" Les dossiers de placement المدروسة من طرف اللجان الولائية للتربية الخاصة في فرنسا هو تغير التشخيصات الطبعقلية "Psychiatrique" للأطفال

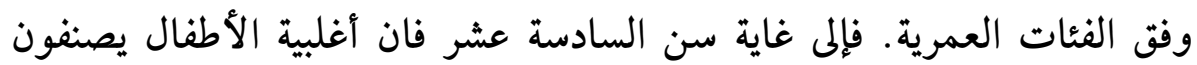

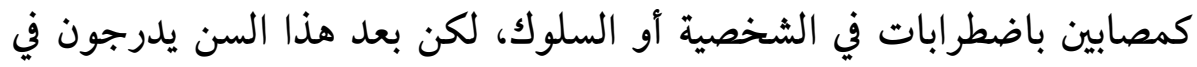
صنف الضعف العقلي المتوسط، وهي وضعية غير معقولة طبيا، ومنه يفترض الباحث أن التشخيص لا يتم على أساس معاينة حقيقة الصحة العقلية للأطفال

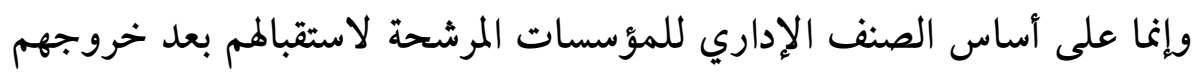

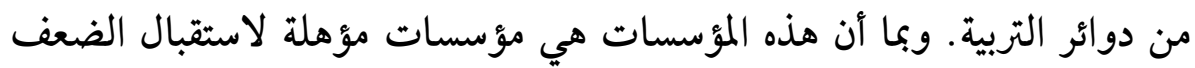




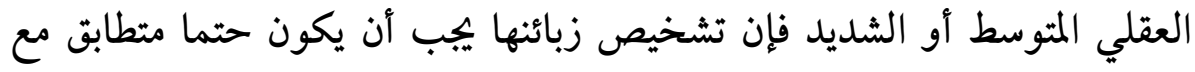

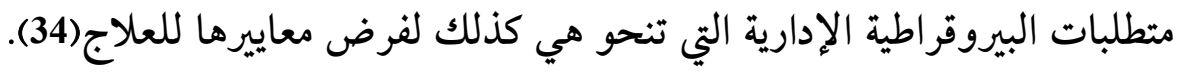

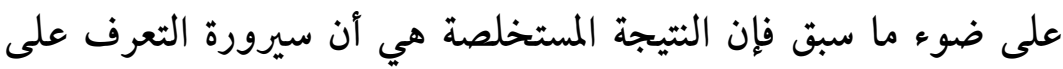

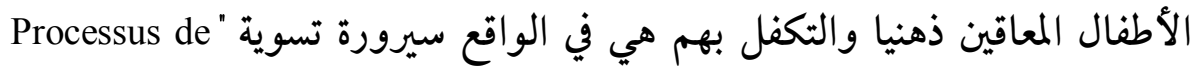
الافعال "Normalisation

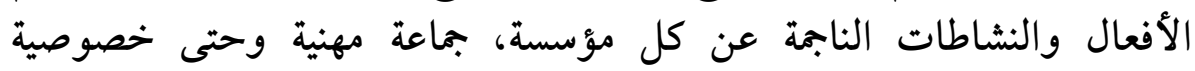

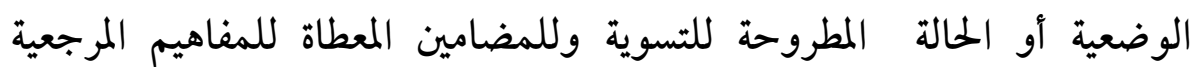

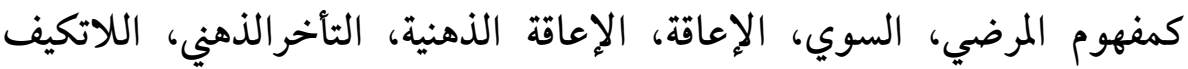

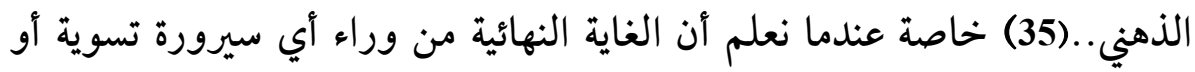

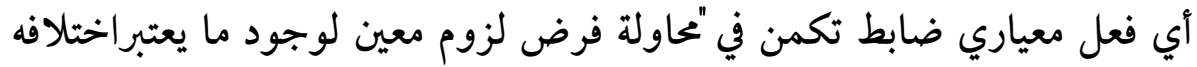
وتباينه في نظر هذا اللزوم مغاير وغريب بل في أكثر منه وكأنه معادٍٍ("36). 
في ختام هذه المحاولة فإننا نؤكد أن الإعاقة الذهنية تأخذ معناها الحقيقي

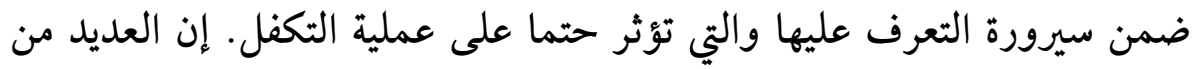

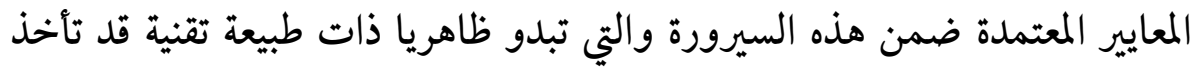

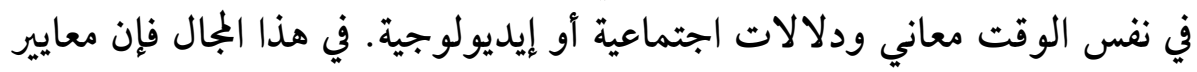

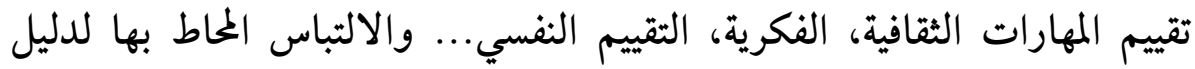

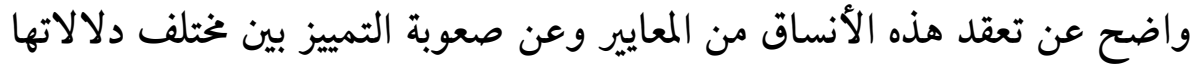

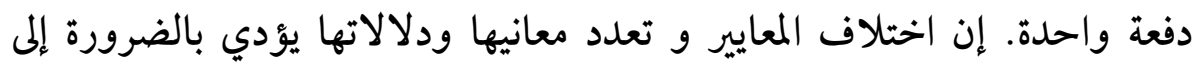
تعقيد سيرورة التسوية التي تنتج عنها.

فهناك كما قلنا بعض المعايير قد تفرض نفسها إلزاميا وهناك البعض

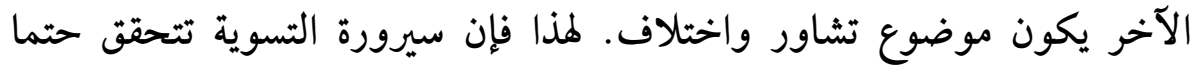

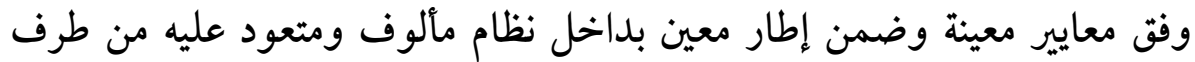
الفاعلين الاجتماعيين الذين يعطونه طابعه الرسمي الظاهر.

من هنا يتبين أن سيرورة التعرف على الأطفال المعاقين ذهنيا و التكفل

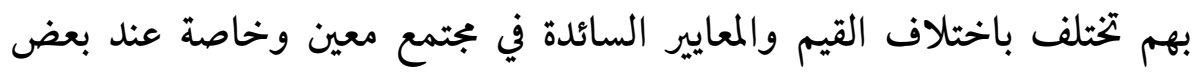
الفاعلين الاجتماعيين الذين يوظفونها وفق تصورات خاصة لتشخيص هذه هذه

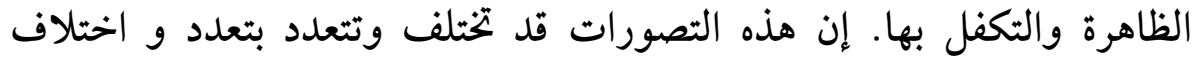

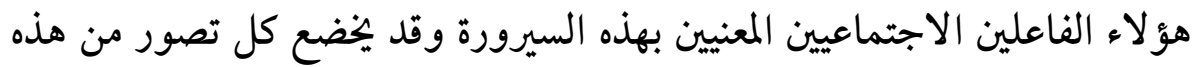
التصورات إلى منطق معين: منطق اجتماعي، منطق اقتصادي، منطق إداري، منطق مئق

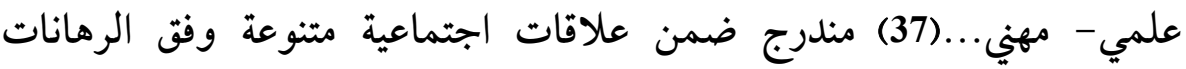
الفردية والجماعية المرتبطة بهذه السيرورة. 


\section{هوامش البحث}

(1) A.Triomphe, S.Tomkiewicz : «Les handicapés de la prime enfance», Paris, Puf, 1985, P62.

(2) الجمهورية الجزائرية الديمقراطية الشعبية: مرسوم تنفيذي رقم12-04 مؤرخ في 04 يناير 2012،يتضمن القانون الأساسي النموذجي لمؤسسات الطفولة المسعفة، الجريدة الرسمية، العدد رقم05 الصادر بتاريخ 29 يناير 2012، صنمن 08.

(3) الجمهورية الجزائرية الديمقراطية الشعبية: مرسوم تنفيذي رقم999-48 مؤرخ في 13 فبراير 1999 ،يتضمن إحداث دور استقبال اليتامى ضحايا الإرهاب وتنظيمها وعملها، الجريدة

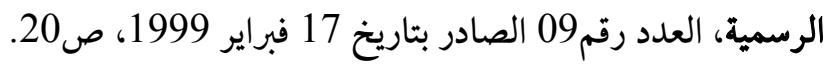

(4) الجمهورية الجزائرية الديمقراطية الشعبية: مرسوم تنفيذي رقمب04-182 مؤرخ في 24

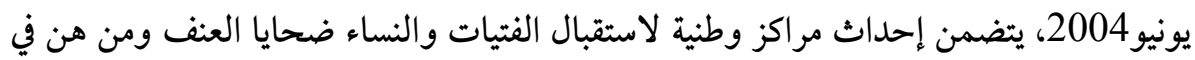

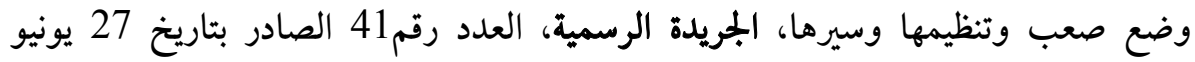

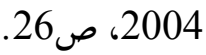

(5) www.msnfcf.gov.dz Le 10/10/2014.

(6) Ibid.

(7) الجمهورية الجزائرية الديمقراطية الشعبية: مرسوم تنفيذي رقم12-113 مؤرخ في 07 مارس2012، المحدد لشروط وضع المؤسسات المتخصصة وهياكل استقبال الأشخاص المسنين

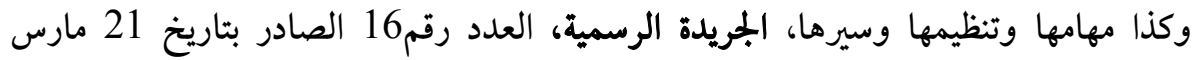

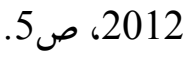
(8) الجمهورية الجزائرية الديمقراطية الشعبية: مرسوم تنفيذي رقم178-178 مؤرخ في 2002

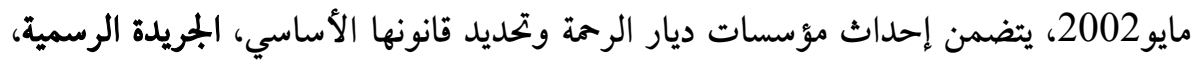

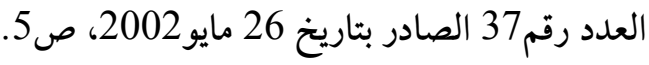


(9) الجمهورية الجزائرية الديمقراطية الشعبية: مرسوم تنفيذي رقم12-165 مؤرخ في 5 أبريل2012، يتضمن تعديل القانون الأساسي النموذجي للمؤسسات المتخصصة في حماية

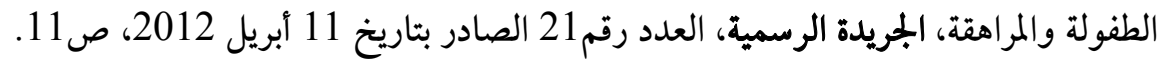
(10) أنظر:الجمهورية الجزائرية الديمقراطية الشعبية: مرسوم تنفيذي رقم 75-64 مؤرخ في 26 سبتمبر1975، يتضمن إحداث المؤسسات والمصالح المكلفة بحماية الطفولة والمراهقة، الجريدة

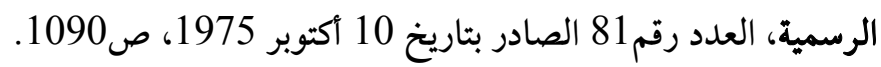
www.msnfcf.gov.dz Le 10/10/2014.

(11) الجمهورية الجزائرية الديمقراطية الشعبية: مرسوم تنفيذي رقم2012-05 مؤرخ في 4 يناير2012، يتضمن القانون الأساسي النموذجي لمؤسسات التربية والتعليم المتخصصة للأطفال

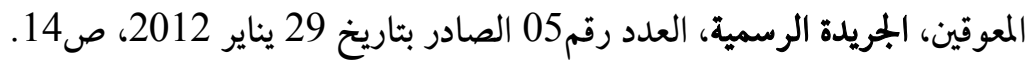
(12) الجمهورية الجزائرية الديمقراطية الشعبية: مرسوم تنفيذي رقمات87-228 مؤرخ في 27 أكتوبر 1987، يتضمن إنشاء مراكز لمن يعانون نقصا في التنفس وتنظيمها وعملها، الجريدة

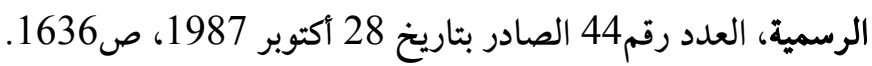

(13) الجمهورية الجزائرية الديمقاطية الشعبية: مرسوم تنفيذي رقم12-05 مؤرخ في 4 يناير2012، مرجع سبق ذكره، ص14. (14) - (14) المرجع السابق، ص14. (15) (15) المرجع السابق، ص15. (16) - (16) المرجع السابق، ص15. (17) - (17) المرجع السابق، ص14.

(18) الجمهورية الجزائرية الديمقراطية الشعبية: مرسوم تنفيذي رقمبماتم-287 مؤرخ في 17

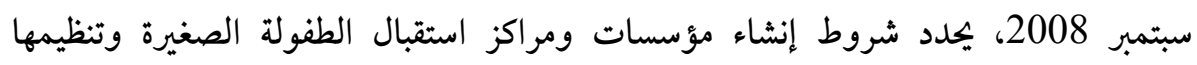

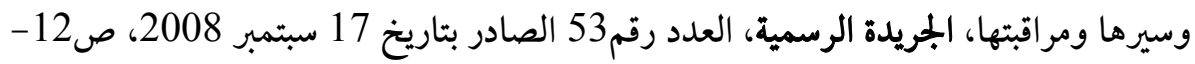


في هذا السياق نجد التعريف الذي ورد في القانون رقم85-05 المؤرخ في 16 فبراير

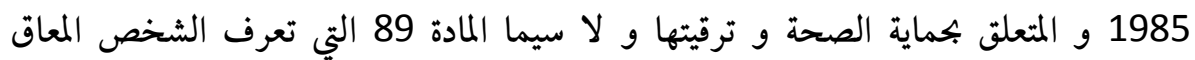

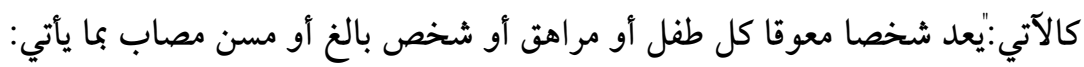
$\checkmark$

$$
\begin{aligned}
& \text { ل إما عجز عن القيام بنشاط تكون حدوده عادية للكائن البشري } \\
& \text { ل إما عاهة تحول دون حياة اجتماعية عادية أو تمنعها". أنظر: }
\end{aligned}
$$

ل الجمهورية الجزائرية الديمقراطية الشعبية:" قانون رقم 85 - 05 المؤرخ في 16 فبراير

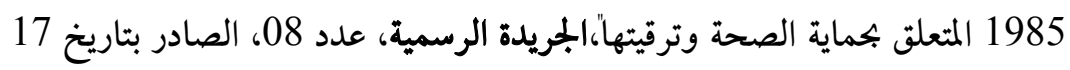

$$
\text { فبراير 1985، ص } 184 .
$$

عبد الرحمن العيسوي: "سيكولوجية الإعاقة الجسمية والعقلية، الإسكندرية، دار الراتب

$$
\text { الجامعية، 1977، صبد الرحن العيدي: } 80 \text { - } 81 .
$$

بلعادي ابراهيم:"الإعاقة العقلية:عناصر تفكيرية في السوسيولوجيا"، مجلة البحوث و

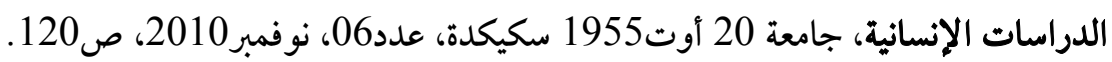
محمد علي محمد وآخرون:"دراسات في علم الاجتماع الطي"، الإسكندرية، دار المعرفة

$$
\text { الجامعية، 1987، ص صلمد } 57 .
$$

$$
\text { (23) (براهيم بلعادي: مرجع سبق ذكره، ص } 120 .
$$

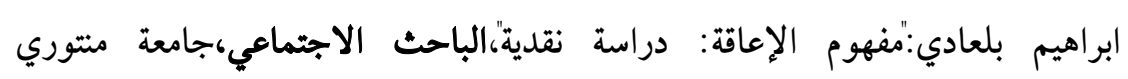

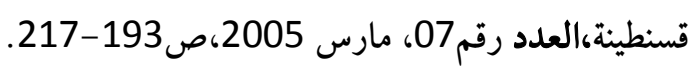

(25) F.Block-Lainé : «Etude du problème général de l'inadaptation des personnes handicapées ", Supplément aux notes et études documentaires, la documentation française, Paris, 1979, P19.

${ }^{(26)}$ S.Tomkiewicz: «Quelques réflexions sur la trilogie de Wood», in CTNERHI : «Classification internationale des handicaps : du 
concept a l'application» Acte du colloque du 28-29.Nov 1988. Paris, Puf, 1988 . P 29.

${ }^{(27)}$ L.Benhabib: «Bab-Eloued: Temoignage d'un pedo-psychiatre». Alger, Opu.1994, P.52.

عند تتاولنا للعلاقة بين الإعاقة العقلية و المرض العقلي. أنظر : ابراهيم بلعادي:

"الإعاقة العقلية:عناصر تفكيرية في السوسيولوجيا"، مرجع سبق ذكره، ص 120 لـ

*قيد بها المراكز المخصصة للتكفل بالأطفال المعاقين ذهنيا.

(29) Voir : B.Ziane: Psychiatrie de l'enfant: Le calvaire continue. «Révolution Africaine », $\quad \mathrm{N}^{\circ} 1364$ du 19 au 25 avril 1990, P08.

(30) Ibid. : P 08

(31) M.Zafiropoulos: «Les arriérés de l’asile à l'usine», Paris, Payot, 1981.

(32)A.Djellali et B.Belaadi : "Les obstacles a l'intégration des enfants handicapés mentaux », Annales des sciences sociales et humaines de l'université de guelma, Université de guelma, $\mathrm{N}^{\circ}$ 4, Juin 2010, P13.

B.Allemandou, B.Belaadi et Autres: «La marginalité sociale en lot et garonne", rapport intermédiaire de recherche sous la direction scientifique du Professeur J.C.Guyot, T2, Les professionnels, les clientèles, M.S.H.A, Bordeaux, 1985, P121.

(34) J.C Guyot : « L'échec scolaire ça se soigne »,toulouse,Privat,1985,P166.

$$
\text { حول مفهوم الإعاقة أنظر: (35) }
$$

$-195$

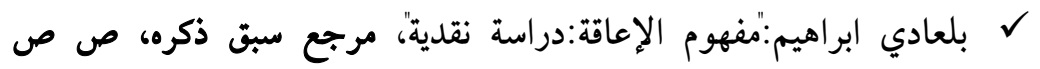

- P. Pitaud: "Contribution à l'analyse du concept d'handicap ", Cahier du CTNERHI, №38, Avril - juin 1987.

- J.H. Stiker: « Corps infirmes et société », Paris, Montaigne, 1982.

(36) G.Ganguilhem: «Le normal et le pathologique». Paris, P.u.f. 1972. $2^{\text {éme }}$.ed. P.177 


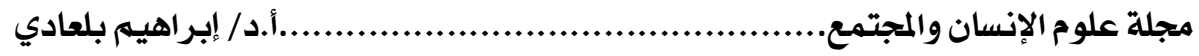

(37) J.C. Guyot «Les normalisations scolaires, sociales et médico-sociales des jeunes handicapés», Cahier de sociologie et de démographie médicale, $\mathrm{N}^{\circ}: 02$, Avril-Juin 1988, PP-134. 